Tohoku J. exp. Med., 1985, 145, 477-478

Short Report

\title{
Unusual Low Affinity of Human Liver Fibronectin for Gelatin
}

\author{
Mamoru Isemura, Hiroshi Munakata, Masashi \\ Kosakai, Yu Yamaguchi, Junichiro Aikawa and \\ Zensaku Yosizawa \\ Department of Biochemistry, Tohoku University School of \\ Medicine, Sendai 980
}

Isemura, M., Munakata, H., Kosakai, M., Yamaguchi, Y., Aikawa, J. and Yosizawa, Z. Unusual Low Affinity of Human Liver Fibronectin for Gelatin. Tohoku J. exp. Med., 1985, 145 (4), 477-478— Fibronectin extracted from the human livers was shown to have very low affinity for gelatin unlike plasma fibronectin. It was demonstrated that this unusual property of liver fibronectin was not due to its proteolytic fragmentation._- fibronectin; liver; gelatin

Fibronectin is a high molecular weight glycoprotein which exhibits a variety of biochemical and biological activities (Yamada 1983). This glycoprotein is most characteristic in that it binds strongly to gelatin (Yamada 1983). We describe here that unlike other fibronectins reported, liver fibronectin has very low affinity for gelatin-agarose.

Liver fibronectin was extracted from the normal human specimens (Isemura et al. 1984c). The urea-extracts were then dialyzed against buffer A (0.05 M Tris- $\mathrm{HCl}$ buffer, $\mathrm{pH}$ 7.5) containing $0.1 \mathrm{M} \mathrm{NaCl}$ and proteinase inhibitors described previously (Isemura et al. 1984c)). The non-dialysable fraction was subjected to affinity chromatography with a column $(1.6 \times 3 \mathrm{~cm})$ of spermine-Sepharose $4 \mathrm{~B}$ (Vartio 1982). The column was washed with buffer $\mathrm{A}$ and then eluted with $4 \mathrm{M}$ urea/1M NaCl in the same buffer.

The results of rocket immunoelectrophoresis (Isemura et al. 1984c) indicated that more than $90 \%$ of liver fibronectin was recovered in the $4 \mathrm{M}$ urea/1M NaCl fraction (data not shown). After dialysis, the fraction was subjected to affinity chromatography with concanavalin A-Sepharose 4B (Isemura et al. 1984a). Rocket immunoelectrophoresis revealed that liver fibronectin was quantitatively bound to and eluted with $10 \mathrm{mM}$ methyl $\alpha$-glucoside from the gel.

Fibronectin thus purified partially was then subjected to affnity chromatography with gelatin-Sepharose 4B (Fig. 1). Liver fibronectin showed very low affinity for gelatin unlike plasma fibronectin. Competitive enzyme immunoassays (Isemura et al. 1984a) revealed that only $29 \%$ of liver fibronectin was bound to gelatin-agarose under the conditions where $94 \%$ of plasma fibronectin was bound. The fibronectin preparations from two other liver specimens gave similar results.

The possibility that liver fibronectin may have been so fragmented proteolytically as to lose its gelatin-binding domain but to retain its antigenic sites was excluded, since the gel-filtration experiments showed that liver fibronectin was largely eluted at the positions earlier than that of plasma fibronectin (Fig. 2).

The possibility that the urea-extract may contain an inhibitor for gelatin-binding was excluded by the experiment in which plasma fibronectin radio-labeled by $S$-alkylation with

Received November 14, 1984; accepted for publication December 14, 1984. 

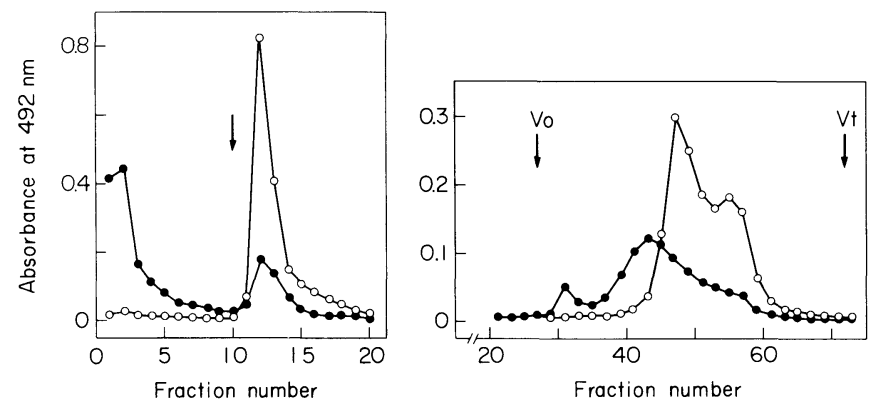

Fig. 1. Affinity chromatography of fibronectin with gelatin-agarose. A solution in buffer A $(2 \mathrm{ml})$ of partially purified liver fibronectin $(\bullet)$ or purified plasma fibronectin $(0)$ (Isemura et al. 1984c) was applied to a column $(1.0 \times 2.5 \mathrm{~cm})$ of gelatin-Sepharose $4 \mathrm{~B}$ as described previously (Isemura et al. 1984a). The column was washed with buffer A and then eluted with $0.1 \mathrm{M} \mathrm{NaOH}$ starting at the position indicated by arrow.

The $\mathrm{NaOH}$ effluents were adjusted to $\mathrm{pH} 7.5$ with acetic acid. Fractions of $2.3 \mathrm{ml}$ were monitored for fibronectin by solid-phase enzyme immunoassay using mouse monoclonal antibodies against human plasma fibronectin (Bethesda Research Laboratories Inc.) and goat peroxidase-conjugated anti-mouse immunoglobulin $\mathrm{G}$ antibodies (Cappel Laboratories Inc.) essentially according to the method described previously (Isemura et al. 1984a).

Fig. 2. Gel-filtration of fibronectin through Sepharose CL-4B. A sample solution (2 ml) of liver fibronectin $(\bullet)$ or plasma fibronectin $(O)$ was applied to a column $(1.5 \times 145 \mathrm{~cm})$ of Sepharose CL-4B pre-equilibrated with buffer A, and the column was eluted with the same buffer. Fractions of $3.2 \mathrm{ml}$ were collected and monitored for fibronectin as described in Fig. 1. Vo, void volume; Vt, total volume.

$\left[{ }^{14} \mathrm{C}\right]$ iodoacetamide (Isemura et al. 1984b) was shown to fully retain the gelatin-binding activity when the pre-incubated mixture with liver fibronectin solution was examined.

Thus the present findings suggest that a largest part of liver fibronectin is polymerized or linked to other macromolecule(s) so as to lose its affinity for gelatin, and provide a new aspect of tissue fibronectins from the structural and functional points of view.

\section{References}

1) Isemura, M., Hsu, C.-C., Yamaguchi, Y., Munakata, H., Yosizawa, Z., Nagai, H., Motomiya, M., Kan, M. \& Yamane, I. (1984a) Biochemical and immunological comparison of fibronectin and polynectin from porcine plasma. J. biol. Chem., 259, 915-921.

2) Isemura, M., Kan, M., Yamaguchi, Y., Munakata, H., Aikawa, J., Yamane, I. \& Yosizawa, Z. (1984b) Further characterization of porcine plasma fibronectin which contains fucosylated carbohydrate chains. Biochim. biophys. Acta, 799, 276-281.

3) Isemura, M., Munakata, H., Kosakai, M., Nomoto, M., Aoyagi, Y., Ichida, F., Nagai, H., Motomiya, M. \& Yosizawa, Z. (1984c) Extraction of fibronectin from human normal and cirrhotic livers. Tohoku J. exp. Med., 114, 217-218.

4) Vartio, T. (1982) Characterization of the binding domains in the fragments cleaved by cathepsin $\mathrm{G}$ from human plasma fibronectin. Eur. J. Biochem., 123, $223-233$.

5) Yamada, K.M. (1983) Cell surface interactions with extracellular materials. Ann. Rev. Biochem., 52, 761-799. 